\title{
THE UNITED KINGDOM ATOMIC ENERGY AUTHORITY
}

$\mathrm{T}$ HE eighth annual report of the United Kingdom Atomic Energy Authority*, covering the year ended March 31, 1962, contains 73 pages, compared with 70 in the previous report. However, the material is arranged in 16 instead of 13 chapters, the new chapters being on magnox reactors and on plasma physics (incorporating fusion research), as well as one on supporting technical developments; that on controlled thermonuclear research has now been dropped. A chapter, "Isotopes and Irradiation Programme", replaces that on "Commercial Operations". Even more noteworthy, for the first time, an estimate is included of the Authority's expenditure on research and development which, over the next five years, is put at about $£ 50$ million per annum. For 1961-62, the current expenditure on this programme was $£ 33$ million with $£ 16$ million on capital expenditure; of this, £2l million was expended on the reactor programme, $£ 4$ million on general reactor technology, $£ 5$ million on general research, $£ 2$ million on plasma physics and fusion research, and $\mathfrak{f l}$ million on isotopes research. Out of 2,740 graduate or professional engineers or scientists employed on the whole programme at March 31, the corresponding deployment at the end of the year was: $1,460,300,520,170$ and 90 . The level of general research is designed to provide the minimum necessary effort on fundamental problems in such fields as nuclear physics, chemistry and metallurgy, together with the essential scientific basis for the Authority's development activities, while that in the field of reactor technology includes work on materials for reactors and for their fuel.

The Authority's non-industrial staff increased slightly during the year, from 20,234 to 20,543 , while the number of industrial employees fell from 20,606 to 20,017. From the review of the Authority's forward civil research and development programme, and the known trends in the weapons and production fields, it seems probable that the total manpower will remain roughly steady for the time being. Recruitment of non-industrial staff was generally satisfactory during the year, but the Authority did not secure quite as many qualified scientists and engineers from the universities as were needed. It is suggested that the wide range of interesting work which will continue to be available for scientific and engineering graduates of many disciplines is not yet fully appreciated. Recruitment of non-industrial staff has recently been confined to younger people, especially those leaving school or completing a first or research degree at university, and this will be the future general policy, so that reliance for the future succession to managerial posts is in the main placed on staff who have made their careers with the Authority.

The net expenditure in 1962-63 is estimated at $£ 67,875,000$ compared with $£ 78,071,000$ in $1961-62$, which included some $£ 6$ million for the National Institute of Research in Nuclear Science, and includes

*nited Kingdom Atomic Energy Authority Eighth Annual Report for the period 1st April, 1961-31st March, 1962. Pp. ix $+87+$
4 plates. (London: H.M.S.O., 1962.) 6s. 6d. net. some $£ 4,881,000$ for research, development and design contracts with industry, the universities, etc. (compared with $£ 4,531,000$ in 1961-62). Commercial sales during the year realized more than $£ 20$ million, with an additional $£ 500,000$ for consulting services and royalties. Sales of isotopes yielded a return on capital of more than 7 per cent. The first two contracts with the Central Electricity Generating Board for fuel elements were signed in May 1961, and a contract to supply fuel for the Latina nuclear power station in Italy in December 1961.

The production reactors and processing plants continued to perform satisfactorily; process efficiencies were improved during the year, and progress on the advanced gas-cooled reactor supported the expectation that electricity generated from such stations will be as cheap as, and later cheaper than. electricity generated from conventional stations in the United Kingdom. In the reactor development programme much experimental work was concentrated on the oxidation of the graphite moderator by the irradiated carbon dioxide coolant. A vigorous programme of research aimed at an economically attractive marine propulsion unit is being carried out in conjunction with the United Kingdom industry, and a working group on marine reactor research has been set up to advise and make recommendations on the programme of research required to advance nuclear propulsion for merchant ships. A team to consider the design of a marine reactor has been formed within the Authority, and a team of engineers has been seconded from the British Shipbuilding Research Association to study the special features of the design operation and safety of a nuclear ship.

During the year, 332 unclassified reports were issued and 390 papers by members of the Authority's staff were published in periodicals. From the topics selected for mention in the chapter on general research and development, only a few can be taken as illustrative. Research at Culcheth on radiation damage in stainless steels containing niobium has given interesting results, and the investigations are continuing to obtain a clear understanding of the phenomena and to determine methods of fabrication and heat treatment which will eliminate embrittlement. A wide programme of general research into ceramic fuels stimulated by their high promise for power reactors includes investigation of the release of fission product gases in irradiated oxide ceramic fuels, the stability of various phases in the uranium-plutoniumoxygen system over a range of temperatures including those used in fuel fabrication and in reactor operation, and the investigation of carbides of uranium and plutonium. Small-scale exploratory studies are being made of the possibilities of direct conversion of heat to electricity, while in nuclear physics improved detectors for eharged particles have been developed at Harwell from silicon which can discriminate between particle energies closely similar in value and respond rapidly to a particle, producing an output signal within a hundred-millionth part of a second. Further 
development of these semi-conductor detectors is directed particularly at establishing production methods and finding ways of making larger detectors.

Basic nuclear research is being carried out with the riew of improving the imperfect understanding of the arrangement of the constituent particles within nuclei and of the forces that hold them together. Work has continued at Harwell on the nature and properties of radioactive aerosols, with particular attention being directed to iodine. A new laboratory designed specifically for remotely controlled experiments of plutonium critical assemblies came into use at Dounreay, and considerable progress was made at the Culham Laboratory site where the objective is the generation of power from fusion reactions. In the extensive research in plasma physics, the key problem is the stability of the plasma and magnetic field system, and the emphasis of the experimental work is on those systems of magnetic confinement thought theoretically to be stable.

\section{THE GHANA SCIENCE ASSOCIATION}

$\mathrm{T}$ HE Ghana Science Association held its second annual congress during June 28-July 1, at the University of Ghana. The highlight of the conference, the start of which coincided with the ending of the Accra assembly on "The World Without the Bomb", was the participation of a number of scientists from various other countries who were in Ghana for the Accra Assembly. The visiting scientists had been informed of this meeting before their arrival in Ghana, and some of them read papers to the Association during the conference, including: Prof. J. D. Bernal (United Kingdom), Prof. Ivan Supek (Yugoslavia), Prof. Gerd Burkhardt (West Ger. many), Sir Robert Watson-Watt (U.S.A.), Prof. Alexjandro Lipschutz (Chile) and Dr. H. Marcovich (France).

The Ghana Science Association is a body in Ghana which is devoted solely to encouraging scientific and technological research and advancing both the understanding and teaching of science. To this end, the Association provides a forum for scientists working in Ghana and guests from outside. It also serves as a medium for informing the public of the part which science and technology are playing and can continue to play in the development of Ghana.

The second annual congress was opened by the Minister Responsible for the National Research Council of Ghana, Mr. Kofi Baako, who deputized for Osagyefo Dr. Kwame Nkrumah, who is president of the Ghana Academy of Sciences-Prof. J. D. Bernal having given a pre-conference open lecture on June 22 on "The Origin of Life". In his opening address, the Minister recognized that science was no magic wand with which to convert poor deserts to rich fertile lands, but that hard work was what was needed in all scientific endeavours. The presidential address was given this year by Dr. S. R. A. Dodu. In his speech, which set a high standard, Dr. Dordu traced in outline the stages of development in the history of medicine. $\mathrm{He}$ observed that contemporary primitive practices are often just echoing fragments of the past activities of pre-scientific man, and that by means of science we are able to dissipate superstitions and fears based on ignorance and to evaluate and assess the traditions and inherited customs by which we habitually order our lives and finally shape the very destiny of mankind.

Later that evening, Dr. H. Marcovich, of the Pastour Instituto in Paris, gave an open lecture, the topic of which was, "Small Doses of Radiation, What are Their Biological Effects?". In his lecture, Dr. Marcovich produced evidence to question the assumption in some quarters that small doses of radiation had no biological effects of any significance.
There were two full sessional days, namely, June 29 and 30 , and on each there were two morning sessions and one afternoon session, each session consisting of three papers. The evenings were taken up by some open items.

The first morning session on June 29 was under the chairmanship of Dr. P. M. J. Phillips, deputy chief medical officer. It was devoted to subjects of medical importance such as "Drugs and the Organization of Mind", by Dr. A. C. Mundy-Castle of the National Institute of Health and Medical Research, Accra; "Age and Tuberculosis Morbidity", by Dr. E. Laing of the Department of Botany, University of Ghana; and "Structure and Activity of the Steroid Hormones", by Prof. J. A. K. Quartey of the Department of Chemistry, University of Ghana. The first of these papers aroused great interest, and the speaker dealt with the varied characteristic disturbances evoked in humans by certain drugs and the investigations being carried out on the biochemical origin of madness. $\mathrm{He}$ also showed cases where similar dis. turbances were induced without resort to chemicals. In Dr. Laing's paper an analysis of variance carried out on tuberculosis morbidity data in parts of Ghana showed a significant positive regression of morbidity with age. Prof. Quartey traced some of the chemical probloms encountered in obtaining hormone substitutes in sufficient quantities for clinical hormone therapy, in particular that of determining the required structural features of the steroid molecule.

The second morning session concerned some aspects of agricultural research, under the chairmanship of K. A. Quagraine, chief scientific officer. The first in this series was a paper by $O$. Snow, adviser on agricultural matters to the Ministry of Agriculture. on "The Economics of Agricultural Research". Recognizing that research is one item in the cost of production, Mr. Snow considered, in an exploratory fashion, the problem in Ghana as to how much money can justifiably be spent on agricultural research, with the provisos that the research is well guided, gives results and is efficiently utilized. The second speaker was P. Ahn of the Faculty of Agriculture, University of Ghana, who read his papor on "Climate, Soils and Agriculture in the Forest Zone" (of Ghana). He showed in an elegant manner how the differences in rainfall in various parts of the forest \%one are related to differences in the type of forest, both in floristic composition and in structure, and also to important differences in the soils. The speaker emphasized that. as a result, both soils and natural vegetation can be correlated with agricultural belts. The final paper in the series, on "Land Capability Classification of the Soils of Ghana", was read by Mr. H. B. Obeng 